\title{
A pediatric case of Bartonella henselae and Epstein Barr virus disease with bone and hepatosplenic involvement
}

\author{
Helena Aparicio-Casares ${ }^{1 *}$, María H. De la Puente-Rico ${ }^{1}$, Covadonga Tomé-Nestal', \\ Juan Mayordomo-Colunga², Estíbaliz Garrido-García², and Cristina M. Suárez-Castañón ${ }^{1}$ \\ ${ }^{1}$ Hospital Francisco Grande Covián, Parres; ${ }^{2}$ Hospital Universitario Central de Asturias, Oviedo. Asturias, Spain
}

\begin{abstract}
Background: Cat scratch disease (CSD) is an infectious disorder caused by Bartonella henselae. The infection usually presents as local lymphadenopathy, fever, and mild constitutional symptoms. Systemic or severe disease is reported in 5-20\% of patients with CSD. We report a case of disseminated CSD with osteomyelitis and hepatosplenic disease and a review of the literature. Case report: A previously healthy 5-year-old male presented with prolonged fever and abdominal pain, followed by low back pain. The serologic test showed positive IgG for B. henselae and IgM and IgG for Epstein Barr virus (EBV). The abdominal ultrasound showed hepatic and splenic hypoechoic lesions, and the magnetic resonance imaging (MRI) revealed spondylitis of the D6 vertebra. He received treatment with azithromycin for 4 weeks and rifampicin for 6 weeks. The symptoms disappeared, and the abdominal ultrasound was normal nine months later. Conclusions: Disseminated CSD is infrequent. The diagnosis requires a high rate of suspicion. Laboratory findings of Bartonella infection are often non-specific. Serologic test, polymerase chain reaction of $B$. henselae in blood or biopsied material of the site of involvement and imaging test can be performed to confirm the diagnosis. The diagnosis of disseminated B. henselae was based on significantly elevated blood titers, radiologic findings, and epidemiologic history. Treatment of CSD depends on the disease presentation. Azithromycin is used as a first-line agent for lymphadenopathy. The optimum treatment and its duration have not been established in atypical or complicated CSD, including patients with osteomyelitis and hepatosplenic disease.
\end{abstract}

Keywords: Cat-scratch disease. Bartonella henselae. Epstein-Barr virus. Osteomyelitis. Hepatosplenic disease.

\section{Un caso pediátrico de enfermedad por Bartonella henselae y virus de Epstein Barr con afectación ósea y hepatoesplénica}

\section{Resumen}

Introducción: La enfermedad por arañazo de gato (EAG) es una patología infecciosa originada por Bartonella henselae. Habitualmente se presenta como linfadenopatía local, fiebre y síntomas constitucionales leves. El 5-20\% de los pacientes con EAG manifiestan una afectación sistémica. Se presenta un caso de EAG diseminada, con osteomielitis y enfermedad hepatoesplénica, y se hace una revisión de la literatura sobre la EAG. Caso clínico: Paciente de sexo masculino de 5 años, previamente sano, que presentó fiebre prolongada y dolor abdominal, seguidos de dolor en la parte baja de la espalda. En

Correspondence:

*Helena Aparicio-Casares

E-mail: helena.aparicio02@gmail.com
Available online: 17-09-2021

Date of reception: $20-09-2020$

Date of acceptance: $29-12-2020$

DOI: 10.24875/BMHIM.20000295
Bol Med Hosp Infant Mex. 2021;78(5):467-473

www.bmhim.com (http://creativecommons.org/licenses/by-nc-nd/4.0/) 
la serología, presencia de IgG frente a B. henselae y de IgM e IgG frente al virus de Epstein-Barr. En la ecografía abdominal se observaron lesiones hipoecoicas en el hígado y el bazo, y la resonancia magnética mostró espondilitis de D6. Recibió tratamiento con azitromicina 4 semanas y rifampicina 6 semanas. Los síntomas desaparecieron y la ecografía abdominal a los 9 meses fue normal. Conclusiones: La EAG diseminada es infrecuente. El diagnóstico requiere un alto grado de sospecha. Los hallazgos de laboratorio en la infección por Bartonella suelen ser poco específicos. Para confirmar el diagnóstico pueden hacerse serología, reacción en cadena de la polimerasa para B. henselae en sangre o en biopsia de tejidos afectados, y estudios de imagen. El diagnóstico de EAG diseminada se basa en títulos elevados en la sangre, hallazgos radiológicos e historia epidemiológica. El tratamiento depende de la forma de presentación. En los casos de linfadenopatía se utiliza azitromicina. En la EAG atípica o complicada, que incluye osteomielitis y afectación hepatoesplénica, no están bien establecidos el tratamiento ni su duración.

Palabras clave: Enfermedad por arañazo de gato. Bartonella henselae. Virus Epstein-Barr. Osteomielitis. Enfermedad hepatoesplénica.

\section{Introduction}

Bartonella henselae, a Gram-negative bacterium, is the causative agent of cat scratch disease (CSD), a worldwide zoonosis ${ }^{1-4}$. The typical reservoir is the cat (particularly young kittens) $)^{1,5}$. B. henselae infections are thought to occur when humans are bitten or scratched by an infected cat ${ }^{1,2,4,6,7}$. It may also be transmitted by cat fleas or ticks ${ }^{4,6-8}$ or by an infected cat licking the non-intact skin of a person ${ }^{1,4,6,7}$. Cat fleas (Ctenocephalides felis) are responsible for horizontal transmission of the disease from cat to cat $^{1,8}$.

Although several genotypes of $B$. henselae have been identified so far, two main genotypes have been designated Houston-1 (Type 1) and Marseille (Type 2). Type 1 is a commonly isolated genotype in humans from Western Europe and Australia, and it is considered more virulent ${ }^{1,9}$.

CSD affects most commonly people $<21$ years of age $^{9}$. Children and teenagers represent about $80 \%$ of patients diagnosed with $\mathrm{CSD}^{6}$. In the United States, the annual incidence of CSD is 4.7 per 100,000 individuals $<65$ years of age and is higher among children between $5-9$ years of age $^{10}$. Other studies report between $54 \%$ and $87 \%$ of cases of CSD in people $<18$ years of age ${ }^{1,11}$.

$B$. henselae infection presents as local lymphadenopathy in $85-90 \%$ of patients ${ }^{8}$, often accompanied by fever and mild constitutional symptoms $\mathrm{s}^{1,2,6}$. CSD is frequently underdiagnosed due to its self-limiting course ${ }^{6}$. Extranodal manifestations with systemic or severe disease are reported in $5-20 \%$ of patients ${ }^{4,5}$. Osteomyelitis is an unusual manifestation of Bartonella observed in $0.1-0.3 \%$ of CSD patients but has been recognized to occur in immune-compromised and immune-competent patients ${ }^{6,12}$. Hepatosplenic lesions appear in $0.3-0.7 \%$ of CSD patients ${ }^{13,14}$.

Because of the difficulty to isolate $B$. henselae in cultures $^{1,3,8,15}$, the detection of DNA by polymerase chain reaction (PCR) and serologic testing is widely used for laboratory CSD diagnosis ${ }^{3}$.

Several studies show that different antibiotics have been used to treat clinical manifestations produced by B. henselae $e^{1,5,6,8,11,12,16,17}$.

\section{Clinical case}

We describe the case of disseminated CSD in a previously healthy 5 -year-old male. The patient came to the emergency department with a fever lasting for 5 days and exudative tonsilitis. We performed throat swab culture and then started oral amoxicillin treatment.

Three days later, the fever persisted. As the throat swab culture was negative, laboratory studies were indicated. The following findings were reported: white blood cell (WBC) count of $14.600 \times 10^{3} / \mathrm{mm}^{3}$ (neutrophil $8.050 \times 10^{3} / \mathrm{mm}^{3}$, lymphocytes $5.010 \times 10^{3} / \mathrm{mm}^{3}$, monocytes $1.140 \times 10^{3} / \mathrm{mm}^{3}$ ) and C-reactive protein (CRP) elevation $(48.91 \mathrm{mg} / \mathrm{L})$. Also, we performed serologic testing for adenovirus, cytomegalovirus, and Epstein Barr virus (EBV). We obtained a positive result for EBV (IgM, IgG, EBNA IgG, and heterophile antibodies) in the serologic testing. Treatment with amoxicillin was discontinued.

Two days later ( 10 days after the fever started), the patient presented abdominal pain. The patient had referred pain in the right hypochondrium upon palpation with no signs of abdominal resistance. The rest of the physical examination was completely normal (no hepatosplenomegaly and no lymph nodes were detected). Another blood test was done with similar results: WBC $12.960 \times 10^{3} / \mathrm{mm}^{3}$ (neutrophil $8.280 \times 10^{3} / \mathrm{mm}^{3}$, lymphocytes $3.710 \times 10^{3} / \mathrm{mm}^{3}$, monocytes $650 \times 10^{3} / \mathrm{mm}^{3}$ ) and CRP $64.87 \mathrm{mg} / \mathrm{L}$. An abdominal ultrasound was requested because of the localized pain. The results 


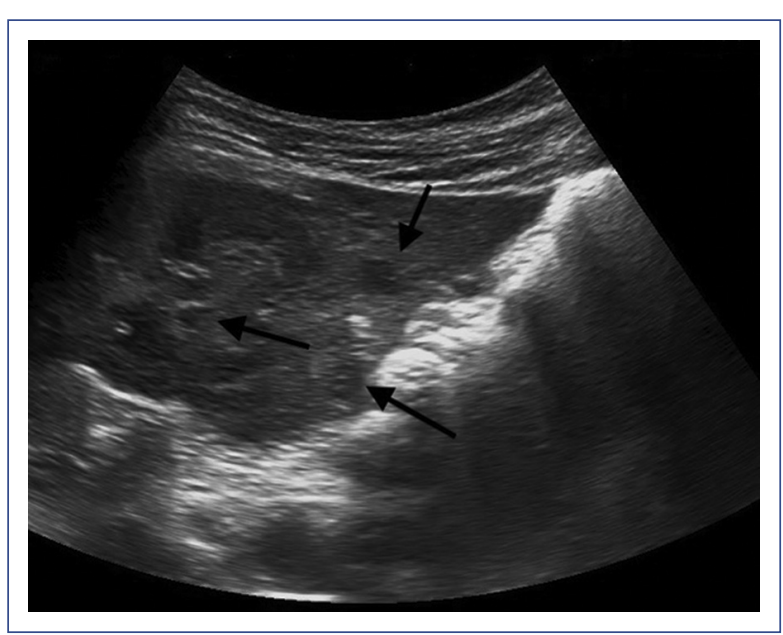

Figure 1. Hepatic ultrasound with hypoechoic lesions. Abdominal ultrasound of a 5-year-old male showing hepatic hypoechoic, not anechoic, lesions. No sign of blood flow after assessment with Doppler ultrasound is noticed. The liver has a normal size, and its outline is homogeneous.

showed hepatic and splenic hypoechoic lesions without hepatosplenomegaly (Figures 1 and 2). The size of the liver and the spleen were $10 \mathrm{~cm}$ and $8 \mathrm{~cm}$, respectively, both normal for the patient's age.

We suspected a zoonosis based on the presence of these lesions, so the family was interrogated about animals at home. The patient revealed that he had been in contact with some kittens two months before. A possible inoculation site was not found. Due to the history and lesions detected in the abdominal ultrasound, the child was admitted to our inpatient unit with a suspected diagnosis of disseminated CSD. Intravenous rifampicin and oral azithromycin were chosen while waiting for results. As the fever persisted despite the treatment, cefotaxime was added to cover other bacterial spectrums. Serologic testing was performed, looking for any zoonosis. The technique employed was indirect immunofluorescence (Focus diagnostics ${ }^{\circledR}$ ). We obtained positive $\lg G$ and negative $\lg M$ of $B$. henselae (other zoonoses tested were negative: Rickettsia, Coxiella, Toxoplasma, Borrelia, Brucella, Francisella tularensis, and Leishmania). Blood and urine culture and stool samples were negative. An ophthalmologist and a cardiologist evaluated the patient, and no problems were detected.

Three days after admission, the patient complained of low-back pain, presenting a good response to analgesic treatment and no neurological damage. The radiography was normal. However, the orthopedist's

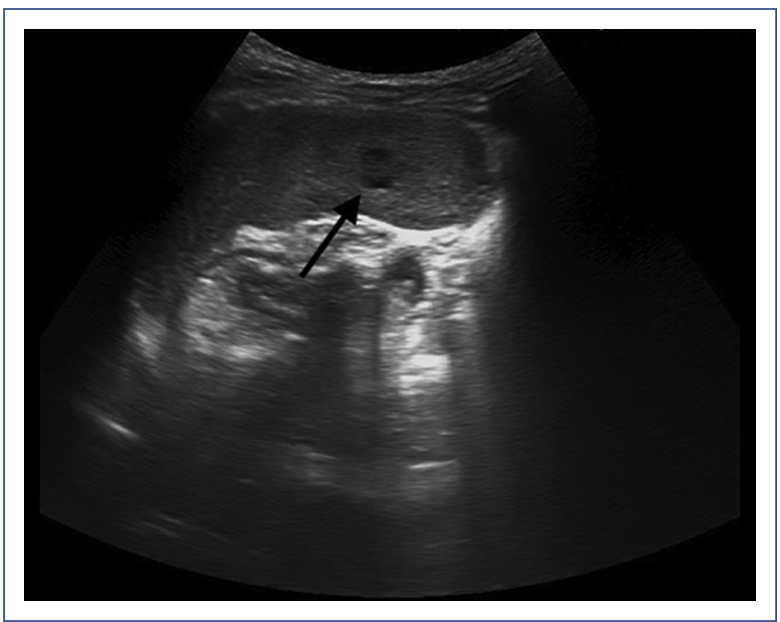

Figure 2. Spleen ultrasound with hypoechoic lesions. Abdominal ultrasound of a 5-year-old male with splenic hypoechoic, not anechoic, lesions. No sign of blood flow after assessment with Doppler ultrasound is noticed. The lesions have a maximum size of $4 \mathrm{~mm}$. The spleen has normal size.

evaluation indicated bone involvement. Therefore, the patient was transferred to a referral hospital for an MRI scan, which showed spondylitis of the D6 vertebra (Figure 3).

The serologic testing was repeated, showing positive $\lg$ 1:256 for $B$. henselae and negative IgM; also, blood PCR of Bartonella was negative. Five days later, the study was repeated with the same results. Furthermore, blood culture, immunoglobulin test, complement test, QuantiFERON, and immunodeficiencies screening were performed, and all showed normal results. A prolonged prothrombin time in the coagulation test (compared to the previous normal study) was detected. This result was interpreted as a process secondary to the acute disease. The patient was treated with vitamin $\mathrm{K}$ for one week after the hospitalization.

The antimicrobial therapy was changed to clindamycin and cefuroxime because of the spondylitis and the uncertainty of CSD diagnosis. Five days later, solitary adenopathy of $2 \mathrm{~cm}$ of diameter, painful to palpation, appeared in the upper right leg. A fine-needle aspiration (FNA) biopsy was performed, and $B$. henselae was identified within this lymph node (PCR positive) by immunohistochemical study.

At that point, the diagnosis of disseminated CSD with spondylitis and hepatosplenic disease was confirmed, so the treatment was changed again to intravenous rifampicin (20 mg/kg/day) and azithromycin (10 mg/kg/day). As a favorable clinical outcome was 


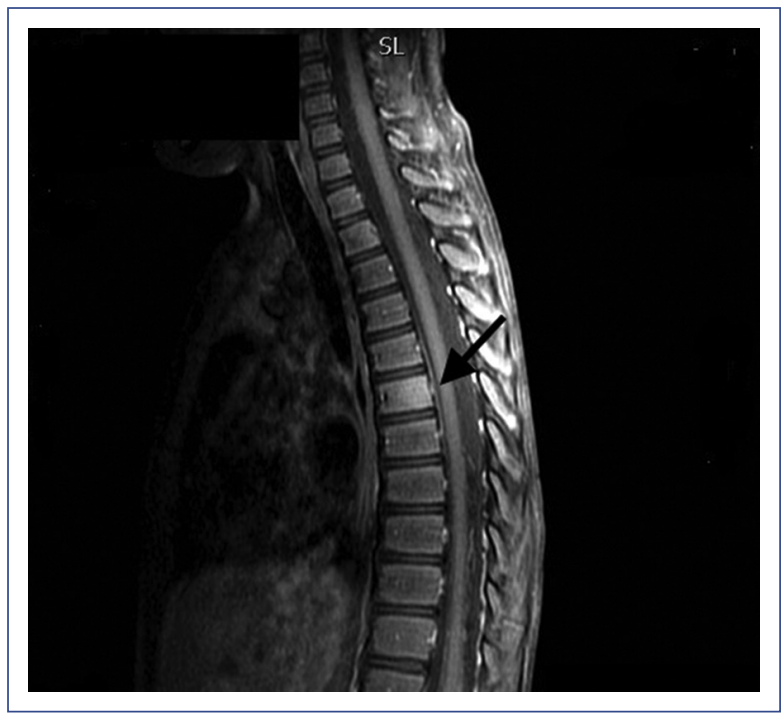

Figure 3. Magnetic resonance imaging showing spondylitis of the D6 vertebra. Magnetic resonance imaging of a 5 -year-old male showing hypointensity in D6 the vertebra. After intravenous contrast administration, the vertebral body shows enhancement. These findings are suggestive of spondylitis.

observed, the patient was discharged. The fever decreased two days after the treatment change, and the low-back pain disappeared five days later. Thus, the patient presented 2 days with fever, while it persisted 11 days after the initial onset of rifampicin and azithromycin and 9 days after cefotaxime. The patient was admitted for 17 days.

The patient follow-up was done at the first hospital. The antibiotic treatment was discontinued two weeks later for azithromycin and four weeks for rifampicin. A low-grade fever continued for three weeks. An abdominal ultrasound was done again two months after the beginning of the illness, finding that hepatic lesions disappeared, and the spleen reduced its size. Nine months later, hepatosplenic lesions and coagulation disorder disappeared.

The patient continued with fatigue for two months. After that, and until the present moment, he has been asymptomatic.

\section{Discussion}

Cat scratch disease begins with an erythematous papule at the site of inoculation. The papule appears 3 to 10 days after inoculation and progresses through erythematous, vesicular, and papular crusted stages. The lesion persists between 1 and 3 weeks ${ }^{1}$. Subsequently, there is a period of 5 to 50 days for the beginning of regional lymphadenopathy ${ }^{11}$ that usually develops 1-3 weeks after the initial skin finding ${ }^{1,4}$. The predominant clinical feature is regional lymphadenopathy, usually ipsilateral, that resolves spontaneously within 2-4 months, but it can last for several months ${ }^{5,8}$. Systemic illness is mild in most patients and can include fever, generalized aches, malaise, anorexia, nausea, and abdominal pain. Less than $10 \%$ of patients have a fever higher than $39^{\circ} \mathrm{C}$, and one-third manifest the disease without fever ${ }^{1}$. The fever can last for two to eight weeks ${ }^{7}$. In the present case, it lasted for one month. Musculoskeletal manifestations, especially myalgia, arthralgia, and arthritis, occur in more than $10 \%$ of patients ${ }^{8}$.

Although infrequent, $B$. henselae can affect almost every organ or system after hematogenous, lymphatic, or contiguous spread $^{6,12}$. Several case studies have described a wide range of atypical manifestations ${ }^{11,13,16,18}$.

Hepatosplenic involvement typically presents with dull abdominal pain, as in this case, and $53 \%$ present with hepatomegaly and splenomegaly ${ }^{1,17}$. Granulomatous lesions in the spleen can be severe enough to result in spontaneous splenic rupture ${ }^{1}$.

Regarding bone involvement, osteomyelitis typically presents as tenderness or pain in the affected area ${ }^{1,6,19}$, as in the case described here. Bartonella osteomyelitis most frequently occurs in the spine ${ }^{1,4,6,19}$. Our patient's MRI showed spondylitis of the D6 vertebra. The pelvic girdle is the most common site of Bartonella osteomyelitis outside of the spine and occurs in $42 \%$ of all non-spinal cases ${ }^{4,6,19}$. Osteomyelitis associated with CSD is usually found distant from any site of lymphadenopathy. This observation suggests a hematogenous or lymphatic spread of the infection ${ }^{1,4,6}$. Bartonella osteomyelitis usually presents subacutely in the axial skeleton, unlike hematogenous osteomyelitis, which presents acutely and typically involves the appendicular skeleton ${ }^{6}$. Patients with osteomyelitis from $B$. henselae infection generally have an excellent prognosis ${ }^{1}$.

Due to the possibility that other atypical manifestations were associated, an ophthalmologist and a cardiologist evaluated the patient (Table 1).

The impact of transient immunodepression during acute infectious diseases on the risk for dissemination of Bartonella infection is still debated. Underlying infections or immunological disorders should be evaluated in all cases of disseminated CSD ${ }^{14}$. Tests in our patient, immunoglobulin test, complement test, 
Table 1. Atypical manifestations of disseminated catscratch disease $\mathrm{e}^{1,8,11}$

\begin{tabular}{|l}
\hline Hepatosplenic disease \\
\hline Parinaud's oculoglandular syndrome \\
\hline Neuroretinitis \\
\hline Facial nerve palsy \\
\hline Encephalopathy \\
\hline Seizures \\
\hline Radiculopathy \\
\hline Aseptic meningitis \\
\hline Guillain-Barre syndrome \\
\hline Cerebral arteritis \\
\hline Transverse myelitis \\
\hline Pneumonia \\
\hline Osteomyelitis \\
\hline Endocarditis \\
\hline Glomerulonephritis \\
\hline Renal disease \\
\hline Arthritis/arthralgia \\
\hline Bacillary angiomatosis \\
\hline Thrombocytopenic purpura \\
\hline Pseudomalignancy \\
\hline
\end{tabular}

QuantiFERON, and immunodeficiencies screening were done with normal results. Regarding EBV infection detected in our case (positive IgM and IgG EBV) is possible that $B$. henselae may have reactivated EBV infection or EBV may have promoted the dissemination of $B$. henselae ${ }^{20}$.

Laboratory findings of Bartonella infection are often non-specific. Infection may result in normal or mildly elevated white blood cell counts and normal, elevated, or diminished platelet counts. Liver enzymes are usually normal. Upon admission, the levels of liver enzymes were aspartate transaminase between 21-26 U/L and alanine transaminase between 11-14 $\mathrm{U} / \mathrm{L}$ in this case. The erythrocyte sedimentation rate may be normal or elevated ${ }^{1}$.

A serologic test was used to confirm the diagnosis. This test has more sensitivity than cultures but lacks specificity because many asymptomatic persons have positive serology due to previous (often asymptomatic) exposure $^{8}$. Initially, when CSD was suspected, $B$. henselae and other zoonoses were analyzed. A positive $\lg G$ and negative $\operatorname{lgM}$ for $B$. henselae were obtained. Blood PCR can be used to differentiate Bartonella; specificity is very high, but the sensitivity is lower than serology ${ }^{8,16}$, with a reported range from $43-76 \% \%^{1,9,17}$. In our case, IgG for $B$. henselae was positive (1:256) and IgM negative. Blood PCR was negative.

The problem with these tests is their analysis. IgG titers greater than 1:256 strongly suggest active or recent infection ${ }^{6,8,16}$, as detected in our case. However, titers between 1:64 and 1:256 represent possible infection; another test should be performed in these patients after 10 to 14 days ${ }^{8}$. Conversely, immunoglobulin $G$ titers less than 1:64 suggest no current Bartonella infection ${ }^{8,9}$. IgG titers decrease with time, with only $25 \%$ of patients remaining seropositive after one year'. We should not forget that a positive $\operatorname{lgM}$ test suggests acute infection but is often elevated only briefly (less than three months ${ }^{1,8,9}$ ) and is commonly normal during the disease $\mathrm{e}^{1,6,7,12}$. It means that negative results do not necessarily exclude disease ${ }^{1,8,9}$. Antigenic variability between the two $B$. henselae serotypes may also explain the inadequate antibody response. Commercial kits use only $B$. henselae strain Houston-1 grown in cell culture as the antigen. Antibodies directed against the $B$. henselae Marseille strain may remain undetected ${ }^{9}$.

PCR testing of blood specimens can detect $B$. henselae DNA in patients with seronegative results. The combined use of serologic testing and PCR on blood specimens is helpful for the noninvasive screening of $\mathrm{CSD}^{3}$.

Finally, in our case, $B$. henselae was identified from a lymph node (PCR positive). The confirmatory test is PCR or direct visualization of $B$. henselae on biopsied material from the site of involvement ${ }^{16}$. Isolation of bacteria from lymph node culture also offers poor yield because lymphadenopathy is thought to be the consequence of an aggravated immune response rather than the bacterial direct invasion and proliferation ${ }^{1,9}$.

Micro-abscesses in the liver or spleen can be detected in more than $50 \%$ of patients with hepatosplenic CSD through abdominal imaging studies ${ }^{17}$. Multiple hepatosplenic lesions are usually small, round, and hypodense on computerized tomography and result from granulomas, abscesses, or lymphoplasmacytic inflammation ${ }^{13}$. 
Osteomyelitis lesions are sometimes subtle on the plain X-rays and may require an MRI or radionuclide bone scan to be found ${ }^{1,6}$.

In this case, hepatosplenic lesion diagnosis was performed by ultrasound and the spondylitis of the D6 vertebra by MRI.

Treatment of CSD depends on the disease presentation. Most patients usually do not require antibiotics because CSD typically resolves within weeks to months regardless of antimicrobial therapy due to its self-limiting nature ${ }^{6,12,16}$. In atypical or complicated CSD, including osteomyelitis and hepatosplenic disease, the optimum treatment and duration have not been established $5,16,17$. Current knowledge on treating atypical or complicated CSD is derived from the observation of case studies rather than randomized trials ${ }^{1,11}$. In the literature, some cases of disseminated CDS resolved without treatment ${ }^{21}$, and others progressed despite antimicrobial therapy ${ }^{4}$.

In vitro, Bartonella species are susceptible to macrolides, aminoglycosides, B-lactams, expanded-spectrum cephalosporins, trimethoprim-sulfamethoxazole (cotrimoxazole), rifampicin, and ciprofloxacin ${ }^{1}$. All antibiotics tested in vitro had only bacteriostatic activity, except aminoglycosides, which demonstrated bactericidal activity ${ }^{1,16}$.

Azithromycin is used as a first-line agent for lymphadenopathy ${ }^{4,6,8,12}$. Single reports on the effectiveness of different antibiotic treatments in CSD suggest the usefulness of azithromycin $(10 \mathrm{mg} / \mathrm{kg} /$ day), clarithromycin (10-15 mg/kg/day), gentamicin (5 mg/kg/day), ciprofloxacin (20-30 mg/kg/day), rifampicin $(20 \mathrm{mg} / \mathrm{kg} /$ day $)$ and cotrimoxazole (40 mg/kg/day of sulfamethoxazole) $)^{11,13,16,19}$.

For patients with osteomyelitis, the recommended treatment is high doses of ciprofloxacin, doxycycline, or azithromycin for extended periods (6-12 weeks, minimum 4 weeks), 10 to 14 days of intravenous treatment followed by oral treatment. The use of two antimicrobial agents together is also recommended ${ }^{11}$. In systemic CSD, a combination of gentamicin and an oral agent such as cotrimoxazole, rifampicin, ciprofloxacin, or azithromycin has demonstrated a favorable response ${ }^{1,17}$.

In our case, when CSD was suspected, azithromycin and rifampicin were started while waiting for the results of laboratory tests. Later, when the fever persisted and the child referred back pain, we decided to associate a third-generation cephalosporin for targeting other bacteria. Because of the spondylitis and the CSD diagnosis uncertainty, the antimicrobial therapy was changed to clindamycin and cefuroxime. When the diagnosis was confirmed, azithromycin and rifampicin were restarted for two and four weeks, respectively. Thus, including the treatment received during admission, the duration of azithromycin was 4 weeks and rifampicin 6 weeks (with 15 days of intravenous treatment for both drugs). Azithromycin was chosen to treat osteomyelitis, and it was discontinued 4 weeks later because the low-back pain disappeared. Rifampicin was chosen to treat systemic CSD and was kept for 6 weeks because the low-grade fever and the fatigue continued.

It has also been described that corticosteroid therapy may be helpful in patients with hepatosplenic CSD and prolonged fever ${ }^{22}$.

The fever can last for two to eight weeks ${ }^{7}$. Our patient presented low-grade fever for three weeks and weakness for two months (possibly related to the EBV infection). In general, symptoms and hepatosplenic lesions remit within 6 months ${ }^{1,13}$. However, there have been rare reports of residual calcification ${ }^{1}$. In this regard, the abdominal ultrasound was normal nine months after the disease in our patient.

The literature search using PubMed MeSH headings "cat scratch disease" and "osteomyelitis" revealed 54 publications, which were reduced to 42 when limiting articles to the population under 18 years of age. If we further limited the search for patients with "hepatosplenic lesions," no publications were available.

Human infection most commonly manifests as regional lymphadenopathy. Although any organ can be involved after bacteremia, osteomyelitis due to $B$. henselae is a rare presentation?

The diagnosis of disseminated $B$. henselae is based on elevated titers, radiologic findings, and epidemiologic history ${ }^{1,6,17}$.

The combined use of serologic testing and PCR on blood specimens is useful for the noninvasive screening of $\mathrm{CSD}^{3}$.

In atypical or complicated CSD, including patients with osteomyelitis and hepatosplenic disease, the optimum treatment and duration have not been established ${ }^{5,16,17}$.

The clinical case presented in this article is infrequent, as indicated by the currently available literature.

\section{Ethical disclosures}

Protection of human and animal subjects. The authors declare that no experiments were performed on humans or animals for this study.

Confidentiality of data. The authors declare that they have followed the protocols of their work center on the publication of patient data.

Right to privacy and informed consent. The authors have obtained the written informed consent of 
the patients or subjects mentioned in the article. The corresponding author has this document.

\section{Conflicts of interest}

The authors declare no conflict of interest.

\section{Funding}

None.

\section{Acknowledgments}

The authors would like to thank the patient's family for giving us access to the clinical data and photographs of complimentary proofs to make the publication of this manuscript possible.

\section{References}

1. Florin TA, Zaoutis TE, Zaoutis LB. Beyond cat scratch disease: widening spectrum of Bartonella henselae infection. Pediatrics. 2008;121:e1413-25.

2. Puri K, Kreppel AJ, Schlaudecker EP. Bartonella osteomyelitis of the acetabulum: case report and review of the literature. Vector Borne Zoonotic Dis. 2015;15:463-7.

3. Yanagihara M, Tsuneoka H, Tanimoto A, Otsuyama KI, Nishikawa J, Matsui T, et al. Bartonella henselae DNA in seronegative patients with cat-scratch disease. Emerg Infect Dis. 2018;24:924-5.

4. Simonton K, Rupar D. Progressive cat scratch disease despite antimicrobial therapy. J Pediatric Infect Dis Soc. 2015;4:e45-e47.

5. Erdem G, Watson JR, Hunt WG, Young C, Tomatis Souverbielle C, Honegger JR, et al. Clinical and radiologic manifestations of bone infection in children with cat scratch disease. J Pediatr. 2018;201:274-80e.12.
6. Mathews DM, Vance KM, McMahon PM, Boston C, Bolton MT. An atypical case of Bartonella henselae osteomyelitis and hepatic disease. Case Rep Pediatr. 2018;2018:2750275.

7. Nakamura C, Inaba Y, Tsukahara K, Mochizuki M, Sawanobori E, Nakazawa Y, et al. A pediatric case with peripheral facial nerve palsy caused by a granulomatous lesion associated with cat scratch disease. Brain Dev. 2018;40:159-62.

8. Klotz SA, Ianas V, Elliott SP. Cat scratch disease. Am Fam Physician. 2011;83:152-5.

9. Chaudhry R, Kokkayil P, Ghosh A, Bahadur T, Kant K, Sagar T, et al. Bartonella henselae infection in diverse clinical conditions in a tertiary care hospital in north India. Indian J Med Res. 2018;147:189-94.

10. Nelson CA, Saha S, Mead PS. Cat scratch disease in the United States, 2005-2013. Emerg Infect Dis. 2016;22:1741-6.

11. Zepeda TJ, Morales SJ, Letelier AH, Delpiano ML. [Bartonella henselae vertebral osteomyelitis: report of a case]. Rev Chil Pediatr. 2016;87:53-8.

12. Donà D, Nai Fovino L, Mozzo E, Cabrelle G, Bordin G, Lundin R, et al. Osteomyelitis in cat-scratch disease: a never-ending dilemma-A case report and literature review. Case Rep Pediatr. 2018;2018:1679306.

13. Wakiguchi $H$, Okamoto $Y$, Matsunaga M, Kodama $Y$, Miyazono A, Seki S, et al. Multiple renal and splenic lesions in cat scratch disease. Jpn J Infect Dis. 2016;69:424-5.

14. Signorini L, Simeone F, Tonegatti L, Colombini $P$, Cadeo B, Cristini F, et al. Co-infection with Epstein-Barr Virus and Bartonella henselae resulting in systemic bartonellosis. J Infect. 2002;45:206-7.

15. Hobson C, Le Brun C, Beauruelle C, Maakaroun-Vermesse Z, Mereghetti L, Goudeau A, et al. Detection of Bartonella in cat scratch disease using a single-step PCR assay kit. J Med Microbiol. 2017;66:1596-601.

16. Rafferty JR, Janopaul-Naylor E, Riese J. Torticollis and fever in a young boy: a unique presentation of cat-scratch disease with vertebral osteomyelitis and epidural phlegmon. Pediatr Emerg Care. 2017;33:e164-e166.

17. Chang CC, Lee CJ, Ou LS, Wang CJ, Huang YC. Disseminated catscratch disease: case report and review of the literature. Paediatr Int Child Health. 2016;36:232-4.

18. Lin CC, Chi H, Tsai JD. Renal microabscesses: a presentation of cat scratch disease. J Pediatr. 2015;166:1544.e1.

19. Karski J, Matuszewski Ł, Okoński M, Pietrzyk D, Karska K, Zaluski M. Cat scratch disease in a 1.5-year-old girl-Case report. Ann Agric Environ Med. 2018;25:345-8.

20. Zbinden R, Kurer SB, Altwegg M, Weber R. Generalized infection with Bartonella henselae following infection due to Epstein-Barr virus. Clin Infect Dis, 1996;23:1184-5.

21. Loeckx I, Tuerlinckx D, Jespers S, Marchant AS, Bodart E. [A clinical case of spontaneous involution of systemic cat scratch disease]. Rev Med Liege. 2010;65:78-80.

22. Phan A, Castagnini LA. Corticosteroid treatment for prolonged fever in hepatosplenic cat scratch disease: a case study. Clin Pediatr (Phila). 2017;56:1291-2. 